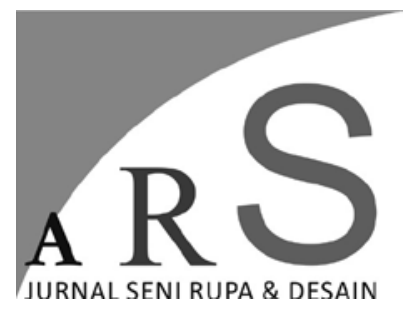

Vol 24 No 1 Januari - Maret 2021 21-32

\section{FUNGSI SIGNAGE MCDONALD'S DRIVE THRU DALAM PERSPEKTIF SOSIAL BUDAYA}

\author{
Naufan Noordyanto \\ Departemen Desain Komunikasi Visual, Fakultas Desain Kreatif dan Bisnis \\ Digital, Institut Teknologi Sepuluh Nopember \\ Tlp.087851267786, E-mail: naufan@its.ac.id
}

\begin{abstract}
ABSTRAK
Layanan drive thru yang ditawarkan McDonald's rupanya menjadi alternatif pilihan masyarakat. Untuk mengidentifikasinya, McDonald's memasang salah satu media komunikasi visual, yaitu signage bertanda drive thru yang terpancang di tepi jalan kota yang erat merespon pola-pola kebiasaan: mobilitas pengendara/pengguna jalan (masyarakat urban). Karenanya, kehadiran signage ini diasumsikan berkontribusi dalam memberi pengaruh pada sendi-sendi kehidupan sosial budaya masyarakat. Penelitian ini menyelidiki fungsi signage McDonald's drive thru dalam perspektif sosial-budaya. Studi dilakukan dengan kajian pustaka dan lebih ditekankan pada analisis deskriptif kualitatif berkaitan dengan fungsi signage McDonald's drive thru yang berpotensi menciptakan dampak sosial, gaya hidup, budaya konsumsi dan komersial. Analisis lebih ditekankan pada implikasi sosial budaya dari objek desain dengan tujuan desain. Fungsi signage McDonald's drive thru sebagai media komunikasi visual (promosi luar ruang) diketahui tidak hanya dipahami secara tekstual saja, yaitu kaitannya dengan fungsi pemasaran, namun juga mempromosikan McDonaldisasi, kapitalisme, konsumerisme, modernisasi, gaya hidup pop dan pop art, serta kehidupan urban.
\end{abstract}

Kata kunci: signage, McDonald's, drive thru, sosial, budaya

\begin{abstract}
McDonald's Drive Thru Signage Function In Social Culture Perspective. The drive-through service offered by McDonald's seems to be an alternative choice of the community. To identify this, McDonald's installed one of the visual communication media, a drive-through signage, with on the side of the city roadthat closely responds to habit: the mobility of drivers that are referred to urban society. Therefore, the presence of this signage is assumed to contribute in influencing the socio-cultural life of the community. This study investigates the function of McDonald's drive-through signage in a socio-cultural perspective. The study was conducted with literature review and emphasized more on qualitative descriptive analysis related to the function of McDonald's drive-through signage which has the potential to create social, lifestyle, consumption culture and commercial impacts. The analysis is more emphasized on the socio-cultural implications of design objects with design objectives. Finally, the function of McDonald's drive-throuh signage as a visual communication medium (outdoor promotional medium) is known not only to be understood textually, namely in relation to the marketing function, but also to promote McDonaldization, capitalism, consumerism, modernization, pop and pop art lifestyles, and urban life.
\end{abstract}

Keywords: signage, McDonald's, drive-through, social, culture 


\section{Pendahuluan}

Sejak didirikan oleh Maurice dan Richard McDonald's (McDonald's bersaudara) pada 1940 di San Bernardino, California, kemudian dikembangkan oleh Ray Kroc sejak 1955, McDonald's, bertumbuh menjadi waralaba global raksasa untuk makanan siap saji (fast food). McDonald's menjadi salah satu dari jajaran merek ternama dan termahal di seluruh dunia. Forbes (2020) menempatkan McDonald's di peringkat ke-10 sebagai the world's most valuable brands pada 2020 dengan brand value senilai USD. 46,1 miliar. Bahkan, di antara para rival industri makanan cepat sajinya, brand value McDonald's memimpin di urutan pertama diikuti Starbucks, KFC, Subway, Domino's Pizza, Pizza Hut (Statista, 1 Juli 2020). McDonald's juga terus meningkatkan jaringan jumlah rumah makannya dari tahun ke tahun. McDonald's mengklaim bahwa rumah makannya telah tersebar di lebih dari 100 negara. (McDonald's Corporation. 2020), Studi yang lebih rinci menunjukkan, McDonald's memiliki sekitar 37 ribuan unit rumah makan pada 2018 (Ritzer, 2018) dan meningkat menjadi 38.695 unit yang beroperasi di seluruh dunia pada 2019 (Statista, 27 April 2020).

Beralih ke Indonesia, berdasarkan hasil kalkulasi penulis dari peta lokasi yang disajikan Mcdonald's Indonesia (2020) dalam laman resminya, lebih dari 200 unit rumah makan atau gerai McDonald's telah beroperasi di Indonesia hingga 2020 (McDonald's Indonesia, 2020). Di antaranya, kurang lebih sekitar 147 unit atau sekitar 67\% rumah makan McDonald's yang beroperasi di seluruh Indonesia memiliki fasilitas drive-through atau lebih dikenal dengan drive thrul layanan tanpa turun (lantatur). Sistem layanan ini memungkinkan pelanggan untuk memesan, membayar, dan mengambil fast food melalui jendela drive thru tanpa harus turun dari kendaraannya (O’Neill, 2020). Sisanya hanya memfasilitasi dine in atau fasilitas untuk menyantap makanan di dalam ruang (indoor). Sejumlah rumah makan McDonald's dengan fasilitas drive thru tersebar di beberapa daerah, meliputi pulau Sumatera (sekitar 22 unit), Kalimantan (sekitar 5 unit), Bali (sekitar 14 unit), Sulawesi (sekitar 10 unit), dan Jawa (sekitar 168 unit). Kota-kota besar seperti wilayah Jakarta, Bogor, Depok, Tangerang, dan Bekasi (Jabodetabek) mendominasi dengan jumlah lebih dari 100 unit rumah makan. Kemudian disusul kota Surabaya (17 unit), Bandung (11 unit), dan Daerah Istimewa Yogyakarta (6 unit).

Dari data-data di atas, ternyata diketahui layanan drive thru McDonald's (bisa dikatakan) menjadi alternatif layanan yang banyak dipilih masyarakat dunia termasuk Indonesia. Sebagai konsekuensinya, di spot-spot rumah makan McDonald's yang menyediakan layanan drive thru, dipasang berbagai media komunikasi visual, salah satunya signage yang terpancang di tepi jalan kota. Signage tersebut dipakai untuk menjalankan fungsi promosi produk McDonald's sekaligus mempromosikan sistem layanan drive thru sendiri yang berkaitan erat dengan pola-pola kebiasaan: mobilitas pengendara/pengguna jalan (masyarakat urban). Karenanya, kehadiran signage ini diasumsikan berkontribusi dalam memberi pengaruh pada sendi-sendi kehidupan sosial budaya masyarakat.

Dari sini, muncul refleksi: apa fungsi signage McDonald's drive thru dalam sosial budaya? Studi ini lebih menekankan untuk mendalami fungsi signage McDonald's drive thru, tidak hanya berkaitan dengan tujuan mencapai keberhasilan komunikasi visual dan pemasaran, tapi juga fungsinya dalam memberi pengaruh dan menyebarkan nilai-nilai sosial dan budaya.

\section{Metode Penelitian}

Penelitian ini menyelidiki fungsi berdasarkan hubungan antara signage sebagai objek desain dengan kehidupan sosial-budaya masyarakat, lalu diwacanakan. Studi lebih ditekankan pada analisis deskriptif kualitatif berkaitan dengan fungsi signage McDonald's drive thru yang berpotensi menciptakan dampak sosial, gaya hidup, budaya konsumsi dan komersial. Analisis lebih ditekankan pada implikasi sosial budaya dari objek desain (penelitian) dengan tujuan desain. 
Selain kajian pustaka, dalam rangka menelusuri pengaruh signage McDonald's drive thru dalam konteks dewasa ini, penulis berupaya mendapatkan sumber lisan dengan memilih beberapa informan, terutama pelanggan atau konsumen yang pernah memakai jasa drive thru McDonald's.

\section{Hasil dan Pembahasan}

Istilah signage seringkali dibahas dalam konsep wayfinding (tanda penunjuk suatu tempat/lokasi) (Rodrigues dkk, 2020). Zijlstra dkk (2016) mendefinisikan wayfinding sebagai suatu tanda/media bantu yang mampu meningkatkan kemampuan pengguna (wayfinding user) untuk bernavigasi di suatu lingkungan dengan menggunakan petunjuk atau tanda pengindikasi seperti signage atau hal lain seperti bangunan terkenal. Dari sini, signage bisa disebut sebagai bagian dari "wayfinding systems", sebagaimana juga disebutkan dalam Whitbread (2001). Dalam Whitbread (2001) pula, karakteristik signage yaitu menggunakan kombinasi simbol dan atau teks sebagai satuan pembentuk visualnya ("signposted using a combination of symbols and text"). Tujuan pemasangan signage adalah untuk membantu pengguna menemukan tujuan/destinasi mereka dengan mudah tanpa bantuan manusia yang memberi petunjuk arah (Rodrigues dkk, 2020). Sehingga kehadiran signage membuat pengguna (signage user) menjadi mandiri dan percaya diri saat menavigasi jalan ke tujuan yang diinginkan (Calori dan Vanden-Eynde, 2015).

Dari pemahaman di atas, maka signage McDonald's drive thru yang diulas penulis sekaligus menjadi batas penelitian ini, yaitu signage dalam bentuk tiga dimensional (3D) sebagai tanda untuk mengidentifikasi, penunjuk lokasi (wayfinding), sekaligus mengandung informasi tentang ketersediaan layanan drive thru pada rumah makan McDonald's yang ditunjukkannya. Mengingat sistem layanan tersebut belum tentu tersedia pada tiap rumah makan McDonald's. Dengan demikian, fungsi signage tidak hanya sebagai penunjuk tempat, tapi juga petunjuk ketersediaan layanan yang ditawarkan. Dari sisi karakteristik visual, logotype "M" atau biasa disebut "the Golden Arches" sebagai identitas perusahaan dipakai/diterapkan menjadi rupa signage. Dengan demikian, signage juga berfungsi menyampaikan komunikasi tentang identitas brand atau "siapa yang menjual".

Maka, dari fungsinya, signage tersebut bersifat komersial ("commercial display signs"), atau berkaitan dengan tujuan pemasaran yang mengidentifikasikan suatu merek korporasi tertentu. Signage yang diproduksi kemudian didisplay atau dipamerkan, ditunjukkan, dan dipertontonkan pada khalayak luas, dengan strategi penempatan umumnya di lokasi strategis pinggir jalan raya, agar mudah dan segera dikenali pengguna jalan/pengendara. Umumnya lokasi yang dipilih adalah kota-kota dengan tingkat kepadatan lalu lintas atau mobilitas masyarakat yang tinggi.

Wujud standar dan universal dari signage gerai McDonald's drive thru yang bisa ditemukan pada masa sekarang ini (di Indonesia) umumnya berbentuk standing signage dan dikemas dengan konsep neon box. Logotype "M" (the Golden Arches) berwarna kuning sebagai inisial dan identitas khas dari McDonald's dikemas dalam bentuk 3D dengan sistem pencahayaan lampu tabung (neon) dalam sehingga sinar lampu yang berpendar di dalamnya dapat diteruskan melalui dua sisi permukaan (Gambar 2). Permukaan yang ditampilkan umumnya datar, namun sisi sampingnya dibentuk mengikuti bentuk (shape) logotype "M" dan bentuk box (persegi panjang) atau trapesium berwarna merah di bawah logotype "M" dengan (atau tanpa) logotype "McDonald's". Elemen grafis dan tipografis tambahan lainnya, seperti box bertuliskan informasi "Drive Thru" (dengan huruf kecil) atau "DRIVE-THRU" (dengan huruf kapital), beberapa terdapat tulisan "buka 24 jam", "Pesan Antar 14045", dan informasi tipografis lainnya lebih cenderung dikemas dengan jenis huruf sans serif (tidak berkait) berwarna putih sebagai elemen grafis dan identitas warna khas dari McDonald's. Bentuk logotype "M" yang simetris serta penyajian 
informasi "drive thru" dalam dua sisi, memungkinkan pengguna jalan dapat melihat dan membacanya dari arah depan maupun belakang.

Konstruksi material dan visual signage tersebut mampu menunjukkan konsistensi penerapan identitas visual dalam wujud bentuk dan warna yang serupa baik siang maupun malam. Jika siang hari, lampu di dalam box tersebut tidak dinyalakan, sehingga identitas warna langsung nampak pada permukaan neon box. Sementara pada malam hari, lampu membantu memberikan pendaran warna dan bentuk mengikuti identitas visual, sehingga mampu membuatnya menonjol di antara lingkungan yang kurang cahaya atau justru gelap. Selain itu, sebagai standing signage, ia dipasangkan pada tiang besi yang dimensi tingginya disesuaikan dengan kondisi lingkungan sekitarnya. Dari temuan, signage McDonald's dengan layanan drive thru demikian biasanya relatif terjaga dari gangguan pandangan, seperti daun dan ranting pohon sekalipun. Hasil pengamatan penulis terhadap signage ini ketika mengemudi di beberapa kota, dari jarak kurang lebih 100 meter, signage ini sudah tampak jelas dari lokasi pengguna jalan raya.

Terlebih lagi, penggunaan bentuk logotype "M" yang khas dan telah populer, legibility (keterbacaan) tinggi, unik, eye cathing, berukuran relatif besar, serta pemakaian warna-warna identitas korporasi (corporate color) kuningmerah-putih sebagai center of interest dari signage, sudah sangat familiar dalam keseharian. Sehingga ia mudah dikenali dan menarik perhatian pengguna jalan dari jarak jauh. Pun pemakaian huruf sans serif pada logotype "McDonald's" dan tulisan "drive thru" dengan karakter sederhana, clean, jelas terbaca, memenuhi persyaratan untuk memudahkan pengguna jalan/pengendara membacanya dari jarak jauh (tertentu) dalam waktu relatif singkat, terutama ketika berkendara. Sebagaimana jenis huruf tersebut cenderung umum dipakai untuk menuliskan informasi pada papan petunjuk jalanatau rambu lalu lintas.

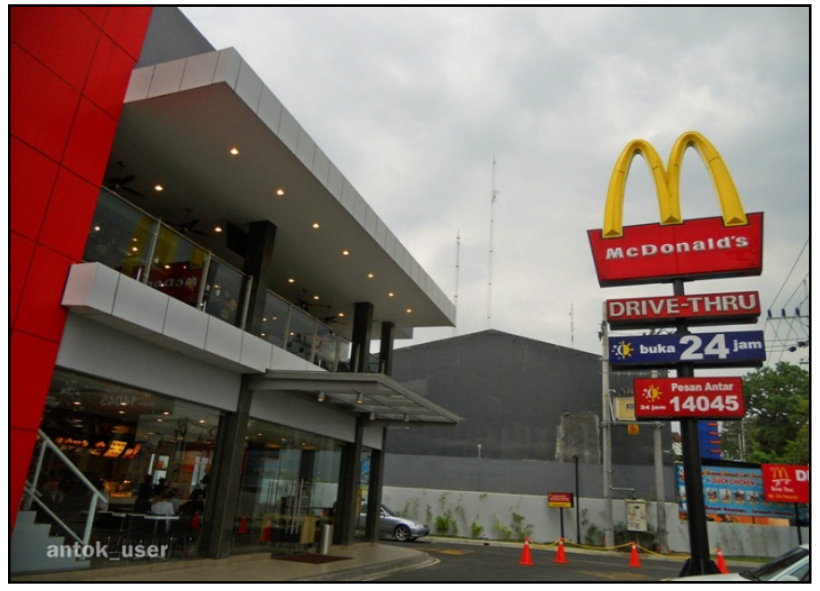

Gambar 1. Signage McDonald's drive thru di Jalan M.T. Haryono, Malang.

(Sumber: Tripdomestik.com, 2018)

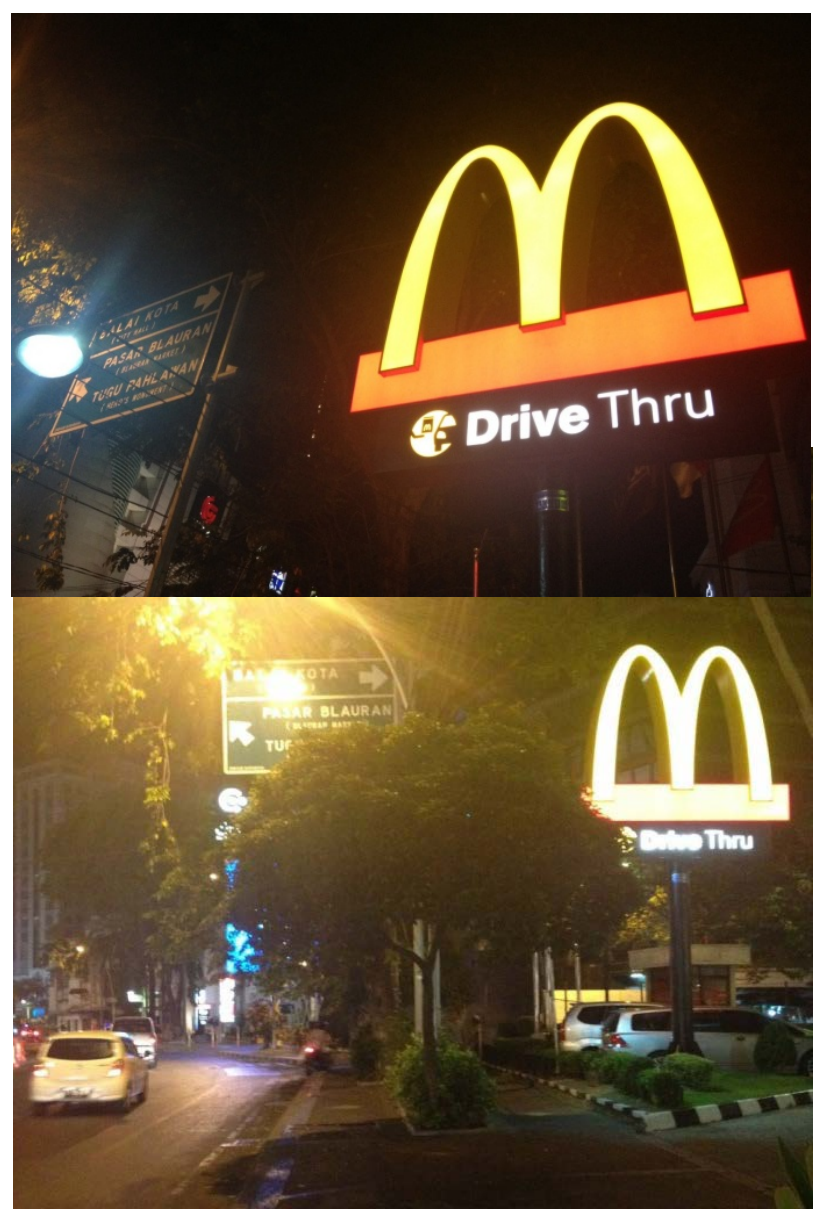

Gambar 2. Signage McDonald's drive thru saat malam hari di Jalan Basuki Rahmat, Surabaya (Sumber: Naufan Noordyanto, 2019) 


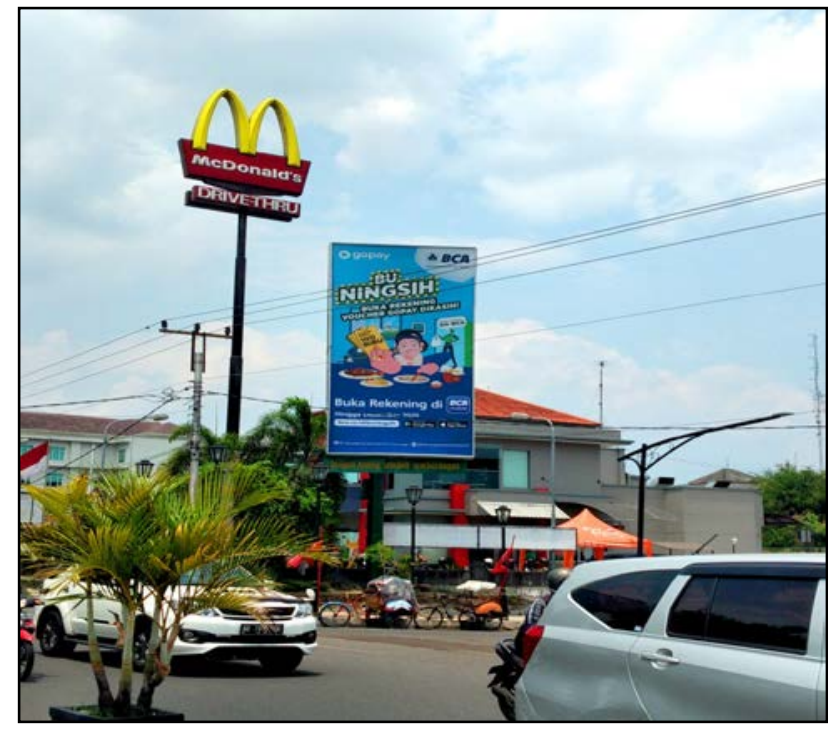

Gambar 3. Signage McDonald's drive thru di Jalan Soedirman, Yogyakarta.

(Sumber: Naufan Noordyanto, 2020)

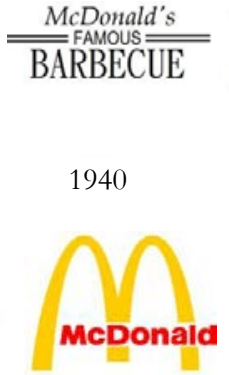

1968

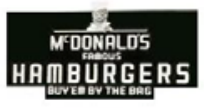

1948

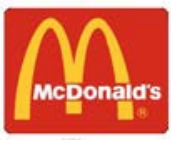

1975

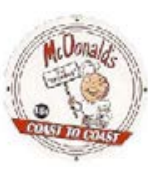

1953

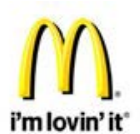

2003

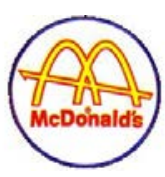

1960

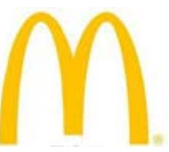

1940
Gambar 4. Perubahan identitas visual McDonald's (Sumber: Designhill.com, 2018)

Logotype atau simbol "M" (the Golden Arches) yang dipakai sebagai materi signage hingga saat ini telah dirilis pada 2006. Karakteristik logotype "M" tersebut lebih sederhana, flat design, dan masih fokus pada golden arches yang memiliki karakter kuat dan telah dikenal publik. Sebelum itu, pada 2003, logotype "M" yang dirilis menonjolkan bayangan/drop shadow (sisi dimensional) sebagai hasil redesain dari logo versi 1968. Logo yang dirilis pada 1968 setelah McDonald's membuka bangunan rumah makan baru, merupakan cikal bakal bentuk logotype " $M$ " modern yang dipakai hingga 2003, sebagai hasil redesain logogram ikon the Golden Arches versi 1960 (Smith, 2006: 12 dan McDonald's Corporation, McDonald's Corporation, 2020). Konsepnya menyederhanakan, menghilangkan garis diagonal pada ikon the Golden Arches (pada logo 1960) dan mensintesiskan ikon tersebut dengan huruf ' $M$ ' sebagai inisial McDonald's. Bentuk ikonik the Golden Arches tahun 1960 ini terinspirasi dari bentuk rumah makan McDonald's pertama yang dibangun di Des Plaines, Illinois, AS (Cowin \& Matusitz, 2016). Bentuk dua lengkungan kuning (arches) di atas atap bangunan rumah makan dan bentuk menyerupai garis diagonalnya diadaptasi dari atap (roof) rumah makan tersebut. Hasilnya adalah transformasi logogram dan type (huruf) sehingga membentuk logotype "M" (Gambar 4).

Sebelum 1960, bisa dikatakan McDonald's belum memiliki logo perusahaan. Meski demikian, McDonald's memiliki identitas visual terutama untuk promosi dan pemasaran. Pada masa awal beroperasi, tahun 1940-1953, identitas visual dipakai pada signage yang dipasang di atas gerai pertama McDonald's di San Bernardino, California. Sejak 1953-1960, McDonald's membuat maskot Speede untuk signage dan promosi lain (McDonald's Corporation, McDonald's Corporation, 2020). Sementara, signage McDonald's drive thru mulai dipakai di atas tahun 1975 setelah McDonald's membuka layanan drive thru pertama di Sierra Viesta, Arizona.

\section{Fungsi signage McDonald's drive thru: analisis} tektual (media promosi luar ruang)

Signage McDonald's drive thru, berdasarkan teori sebagaimana dipaparkan di muka, adalah sistem tanda terutama menunjukkan ketersediaan layanan tanpa turun atau pesan bawa pulang. Lantas bagaimana fungsi penandaan ini menjalankan perannya? Beberapa fungsi dari signage McDonald's drive thru berkaitan dengan tujuan mencapai keberhasilan komunikasi pemasaran, penulis uraikan dalam berbagai asumsi analitis.

Signage ini membantu pelanggan dalam 
menentukan pilihan konsumsi dengan cepat akibat "kesibukan" di jalan raya. Hal ini juga mendukung mobilitas pelanggan yang barangkali tengah melalui atau berada di lingkungan kota. Sehingga layanan drive thru dapat menjadi alternatif yang memungkinkan untuk pelayanan yang cepat. Adanya drive thru tentu saja memudahkan pelanggan yang sibuk dengan aktivitas dan mobilitas tinggi, dengan penyajian makanan siap saji yang memungkinkan untuk makan di perjalanan.

Beberapa orang yang penulis wawancarai, menyampaikan alasan terkait keputusannya memilih layanan drive thru adalah karena alasan kesibukan yang menuntut kesegeraan, malas turun dari mobil, atau malas parkir, atau justru karena sedang malas nongkrong. Drive thru juga memungkinkan pemenuhan keinginan karena kemudahan yang ditawarkannya, di antaranya adalah layanan tanpa parkir (yang biasanya relatif merepotkan dan di kota besar tarifnya relatif mahal), kemudahannya dalam mencapai akses karena jangkauan keberadaannya yang cenderung strategis (di pinggir jalan), selain karena ketersediannya yang umumnya aktif 24 jam. Adanya signage membantu mereka untuk memutuskan pemenuhan hasratnya tersebut ketika sedang di jalan. Pelanggan dapat menggunakan layanan drive thru yang cepat dan mudah, untuk kembali melanjutkan perjalanan menuju aktivitas yang lain. Karena alasan di atas, meski melihat signage McDonald's namun bukan bertanda ketersediaan layanan drive thru, calon pelanggan yang demikian tetap tidak akan membeli produknya, kecuali tersedia layanan drive thru. Dengan kata lain, dapat diketahui, signage yang demikian membantu pemenuhan motivasi konsumsi berbasis kebutuhan pelayanan, bukan hanya pada "siapa yang menjual" lewat identitas (logo) yang ditampilkan pada signage.

Kendati demikian, soal siapa yang menjual juga penting dipresentasikan dalam materi signage. Hal ini terjadi karena signage McDonald's drive thru yang menggunakan/menerapkan identitas visual yang cenderung seragam di beberapa tempat. Signage bisa dibilang memiliki kemampuan untuk meningkatkan efisiensi akan keputusan pembelian karena mampu memberikan bayangan (mental) akan informasi tentang produk dan lokasi penjualannya. Ia membuat calon pelanggan tidak hanya segera dapat mengidentifikasi, tapi juga mengingat segala hal yang berkaitan dengannya, tentang kualitas produknya, pelayanannya, dan sebagainya. Sehingga prinsip efisiensi, yang oleh Ritzer (2008) dijabarkan dalam hal menghemat waktu, sudah direpresentasikan oleh signage McDonald's bertanda drive thru. Dengan kata lain, hadirnya signage layanan drive thru, yang menampilkan logo ikonik McDonald's di pinggir jalan, membantu masyarakat untuk mengatasi keraguan akan kualitas (memberikan kesan akan jaminan kualitas) dari produk yang ditawarkan. Apalagi ketika calon pelanggan berada di wilayah atau kota baru yang menyebabkan dirinya ragu akan kualitas berbagai pilihan makanan di lingkungan sekitarnya. Kehadiran signage tersebut membantu calon pelanggan untuk mengingat kembali janji, kualitas, atau produk yang ditawarkan McDonald's.

Karena signage McDonald's memakai logo mereka, maka bisa dibilang McDonald's menjual merek. Sehingga masyarakat (calon pelanggan) dibantu untuk memilih produk dan layanan aslinya, mengingat kekuatan merek McDonald's sudah dikenal luas. Calon pelanggan yang loyal terhadap merek ini tentu sudah percaya dan memakai layanan dan produknya. Dan signage-lah media luar ruang yang dipakai untuk "berinteraksi" dengan khalayak tersebut.

Di samping itu, berdasarkan wawancara penulis kepada beberapa pelanggan, ternyata hadirnya signage dapat memunculkan realitas tertentu, terutama perilaku psikologis pelanggan. Signage yang dilihat calon pelanggan secara tibatiba saat berkendara, dapat menumbuhkan atau menstimulasi hasrat konsumsi yang tak terduga. Pelanggan yang semula tidak memiliki rencana untuk mencoba menu McDonald's menjadi "ingin" bukan karena butuh. Ini mula-mula karena selain materi visual signage tersebut mudah dikenali, juga biasanya ia kelihatan sangat jelas 
dari kejauhan, mengambil ruang pandang pengguna jalan, lalu menciptakan efek stimulatif. Dalam hal ini, signage tersebut dipersonifikasikan seolah-olah menjadi "orang" yang sedang "melambaikan tangan" sebagai alat bujuk untuk mempengaruhi calon pelanggan atau pengguna jalan agar mengikuti apa yang dikehendaki keinginan penyajinya (produsen). Ia menjadi pengganti hadirnya staff promosi penjualan (sales promotion person) yang menjangkau khalayak luas di luar ruang.

Di samping itu, adanya signage selain untuk mengidentifikasi lokasi keberadaan drive thru, juga menjadi marking atau alat penanda fisik untuk pemetaan lokasi atau rencana jika calon pelanggan baru mengetahui dan tidak sedang ke lokasi. Ia seperti fungsi pin digital pada Google Maps yang menandai dan menyimpan posisi dari lokasi yang diinginkan dan dituju. Hal ini turut mengindikasikan bahwa signage menstimulasi pelanggan untuk merencanakan kegiatan konsumtifnya. Jika suatu perencanaan dilakukan dalam jangka panjang maka akan menanamkan budaya konsumtif yang kuat.

\section{Fungsi signage McDonald's drive thru dari perspektif sosial budaya (analisis kontekstual)}

Ulasan tentang signage McDonald's drive thru tidak dapat dilepaskan pada pembahasan dalam konteks sosio kultural, yang berkaitan dengan pengaruhnya pada sikap, nilai, dan gaya hidup masyarakat.

Secara umum, penggunaan signage adalah representasi dari cara berkomunikasi dalam tatatan sosio kultural kota. Maksudnya, signage tersebut adalah media komunikasi instrumental yang merepresentasikan cara berkomunikasi masyarakat urban. Kehadirannya berkebalikan dengan sistem komunikasi interpersonal ala masyarakat tradisionalis yang memerlukan kehadiran manusia untuk menunjukkan suatu tempat atau jalan. Signage merupakan media yang digunakan untuk berkomunikasi pada pengguna jalan, sebagai pengganti manusia. Memandang konsep berkomunikasi yang demikian, dikatakan Barker (2015: 315), gaya hidup kehidupan kota atau masyarakat urban, mendorong adanya impersonalitas dan mobilitas karena "kehidupan kota didasarkan pada sejumlah besar orang yang hidup berdekatan, namun tanpa benar-benar mengenal satu sama lain, sehingga mengharuskan mereka menjalankan transaksi instrumental, bahkan insidental, dengan mengabaikan pertemuan intensif di antara mereka." Dalam hal ini, keberadaan signage layanan drive thru McDonald's semakin mengafirmasi konsepkonsep kehidupan masyarakat urban yang mobile tersebut.

Keberadaan signage sering diasosiasikan dengan praktik-praktik modernitas yang diusung McDonald's. Keberadaan signage dan tentu saja rumah makan McDonald's tersebar di kota-kota besar dan di sekitar jalan raya memunculkan sebuah citra dan kesan bahwa jalan raya yang merupakan sarana publik diintervensi (dalam komunikasi) oleh praktik komersial yang dianggap bergengsi, mahal, dan lebih modern (di Indonesia). Terlebih lagi, di beberapa tempat, posisi rumah makan McDonald's biasanya berjejer dengan beberapa toko dan butik bermerek besar lainnya, misal di Mall, yang membawa pengaruh-pengaruh modernitas. Sehingga dalam konteks ini, signage merupakan media untuk mempromosikan nilai-nilai kemajuan dan modernitas. Pun kehadiran signage drive thru sering disandingkan dengan gaya hidup manusia modern. Pola konsumsi makanan cepat saji dan pelayanan drive thru, merupakan kebiasaan yang biasa dilakukan oleh masyarakat urban yang notabene cenderung memiliki mobilitas tinggi dan pandangan modern. Ruangruang dalam mobil/kendaraan dihadirkan menjadi ruang konsumsi makanan bagi masyarakat urban. Berbeda dengan nilai-nilai masyarakat tradisional yang barangkali mengedepankan pelayanan yang "relatif lama", karena adanya intensitas kontak sosial, adat makan, dan lain-lain yang dianggap penting.

Kota dianggap sebagai tempat lahir estetika modernisme (Barker, 2015: 315). Berdasarkan konsep ini, signage, sebagai karya desain dan media komunikasi visual, yang dipasang di 
jalanan kota, sekaligus entitas yang diwakilkannya (McDonald's) dianggap mewakili modernitas. Ini bisa dilihat dari sistem dan konsep yang dibawanya, seperti mempromosikan nilai-nilai efisiensi sajian makanan dan pelayanan drive thru. Sehingga berkontribusi dalam memberi pengaruh pada kesadaran dan perhatian masyarakat urban (calon pelanggan) terhadap signage di jalan.

$\mathrm{Hal}$ ini mengingatkan pada penggunaan signage di masa-masa awal perkembangan industri makanan siap saji Amerika yang dipengaruhi oleh automobile (mobil) dan minat masyarakat terhadap keberadaannya.

Diuraikan dalam Smith (2006), ketika mulai muncul di AS sekitar tahun 1890-an, mobil menjadi barang mewah yang hanya dimiliki orang-orang kaya. Era mobil yang relatif lebih murah dimulai saat Henry Ford memproduksi massal mobil jenis pertamanya pada 1908. Pasca Perang Dunia I, penjualan mobil di AS meningkat drastis. Sekitar 9,2 juta mobil, truk, dan bus beroperasi di AS pada 1920. Kebutuhan akan mobil semakin meroket pasca Perang Dunia II karena orang-orang kembali ke rumah dan kembali menjalani kehidupan bersama keluarga. Keranjingan masyarakat Amerika terhadap penggunaan mobil kemudian memunculkan jenis dan pola baru rumah makan yang mengakomodasi kebutuhan-kebutuhan pengendara (Smith, 2006). Akibatnya, berkembanglah rumah makan yang dekat dengan jalan raya dengan menu-menu makanan baru yang simple dan disajikan cepat (fast food) dan pelayanan yang memudahkan. Pada perkembangannya, konsep-konsep layanan rumah makan yang mengakomodasi pengendara tersebut dibuat dalam sistem drive in, drive up, hingga drive thru yang bisa dinikmati hingga kini.

Saat itu, ditemukan permasalahan dalam pemasaran, seperti seringnya pengemudi dan penumpang yang mengendarai mobilnya dengan cepat, begitu mudahnya tidak sadar dan melewatkan bangunan rumah makan karena tidak ada tanda tertentu yang jelas yang mempromosikannya. Imbasnya, sejak 1920-an, muncul kebutuhan akan sign system (sistem tanda visual, termasuk nama/tipografi) luar ruang, yang dibuat untuk mengidentifikasi dan meningkatkan awareness calon pelanggan rumah makan, terutama fast food (Smith, 2006). Dalam praktiknya, signage yang berukuran relatif kecil sangat sulit dibaca pengendara dari mobil yang sedang melaju. Maka dalam perkembangannya, dipasanglah signage dalam ukuran relatif besar. Pada malam hari, agar tetap terlihat, tanda-tanda tersebut diberi lampu. Sehingga di kemudian hari neon sign menjadi umum.

Pada masa-masa awal pendirian McDonald's, signage dipakai sejak gerai pertama dibuka oleh Richard dan Maurice McDonald (McDonald bersaudara) di San Bernardino, California, pada 1940-an. Setelah ditutup selama 3 bulan, pada Desember 1948, McDonald bersaudara membuka kembali gerai McDonald dengan sistem self service-drive in (McDonald's Corporation, 2020). Konsep drive in yaitu makanan yang diantarkan pelayan (yang disebut tray boy atau tray girl, dan berubah carhop pada 1930-an) kemudian disantap di dalam mobil yang sedang berhenti (parkir) di sekitar gerai tersebut. Parkir mobil-mobil pelanggan adalah bagian dari lansekap rumah makan. Pada saat itu, signage utama yang dipasang di atas gerainya, dituliskan nama McDonald's Famous Hamburgers dan menu utama hamburger seharga USD. 15 sen. Signage ini terlihat dari kendaraan yang melaju jalan (2006: 36 dan 80).

Momentum drive thru semakin menanjak ketika McDonald's memulainya pada 1975 (Gambar 5), dan memasang signage drive thru pertamanya di Arizona (Gambar 6). Sebagian besar, rumah makan fast food telah memiliki jendela drive thru sejak1976. Penelitian pada 1980 mencatat peningkatan pelanggan drive thru di rumah makan McDonald's sebesar 37\% (Penfold, 2008: 158). Kemudian pada 1982, penjualan fast food melalui drive thru meningkat sebesar 51\% (Smith, 2006: 83).

Pada 1975, sistem layanan drive thru dalam industri makanan cepat saji sebenarnya bukan hal yang baru. Sistem drive thru diperkirakan telah ada setelah Perang Dunia I (1914) di ranah 


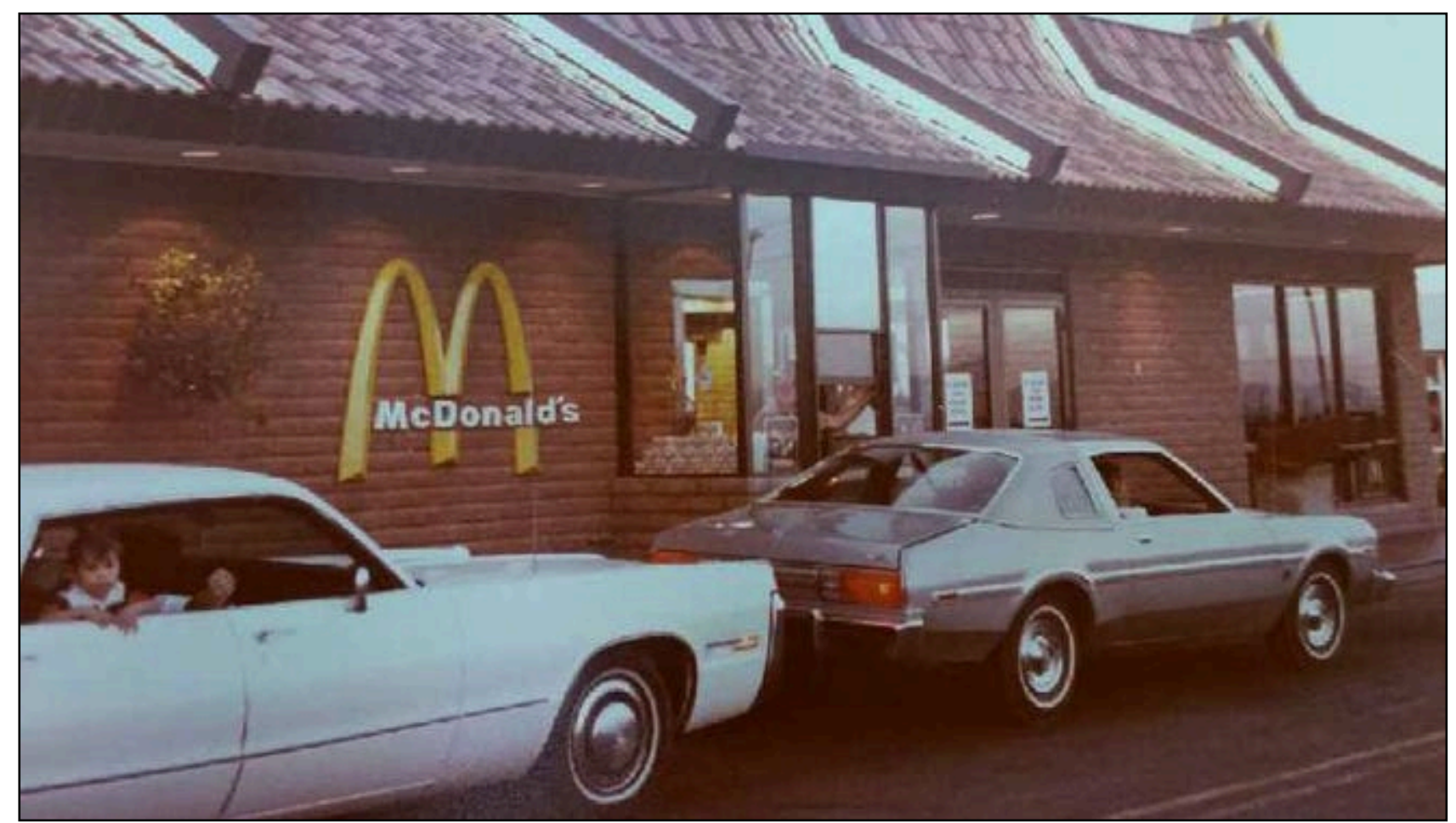

Gambar 5. Jendela drive thru pertama McDonald's, di Sierra Vista, Arizona, diperkirakan pada 1975.

(Sumber: Azcentral.com, 2016)

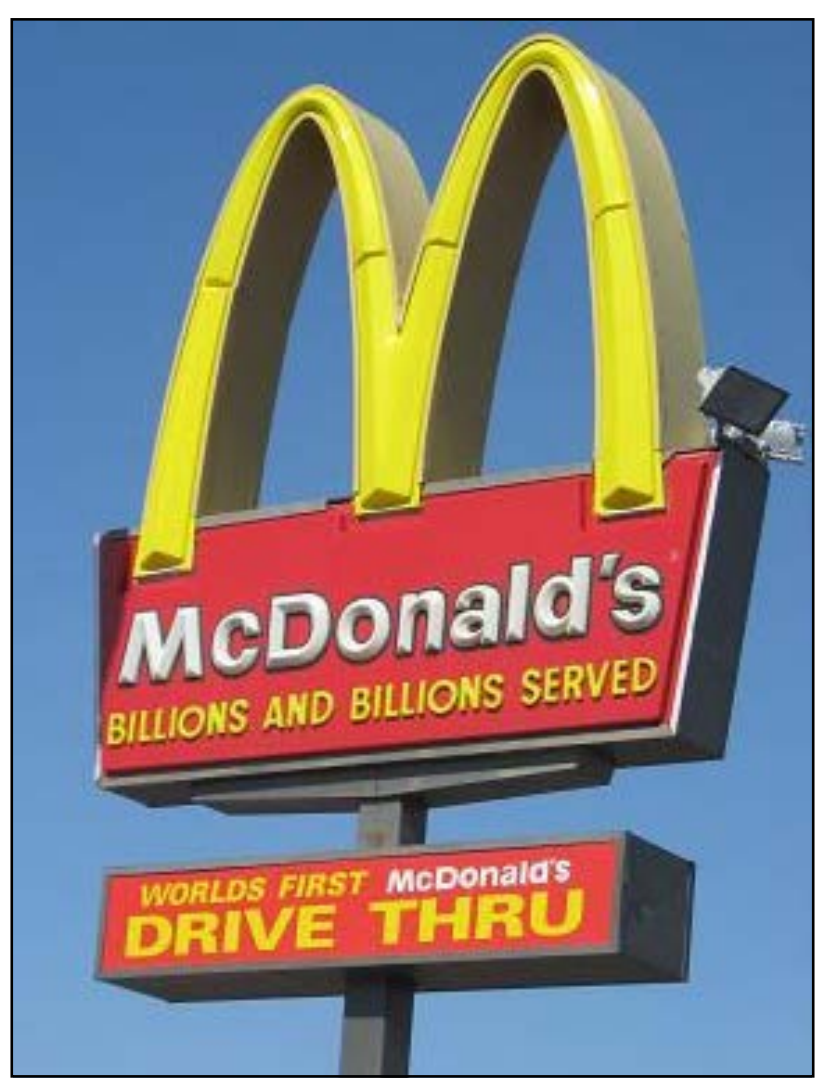

Gambar 5. Signage McDonald's drive thru pertama, di Sierra Vista, Arizona, diperkirakan sejak 1975.

(Sumber: Waymarking.com, 2008) industri fast food. Menurut Penfold (2008: 158), cikal bakal sistem tersebut dimulai sejak berkembangnya sistem jendela "drive up" yang memungkinkan pelanggan untuk membeli makanan dengan mendekatkan jarak mobilnya (drive up) pada jendela pelayan (drive up window). Mekanismenya yaitu pelanggan keluar dari mobilnya, kemudian memesan, membayar, sekaligus mengambil makanan yang dilakukan pada satu jendela tersebut, lalu kembali dan menyantap makanan di mobil (Smith, 2013: 282).

Perkembangan drive thru modern yang menginspirasi di masa depan, dimulai oleh perusahaan In-N-Out Burger pada 1948 di gerai pertamanya yang berlokasi di Baldwin Park, California. In-N-Out Burger memasang speaker box dua arah yang memungkinkan pelanggan memesan makanan dari dalam mobil melalui alat komunikasi yang langsung disampaikan/ didengar pelayan di dapur sehingga meningkatkan kecepatan proses pemesanan. Semenjak itu, perusahaan makanan cepat saji lainnya mengikuti jejak sistem drive thru dari In-N-Out Burger, 
seperti Jack in the Box dan Burger King memulainya pada 1950-an dan Wendy's yang didirikan pada 1969 memulainya pada 1971 (Smith, 2006: 82). Saat ini, sistem pemesanan pada pos drive thru McDonald's dilakukan dengan berbicara melalui alat COD (Customer Order Display) setelah pelanggan memutuskan pilihan menu pada menu board.

Berdasarkan tinjauan sosio-historis di atas, konsep drive thru dan signage yang mempromosikannya tersebut memiliki relevansi dalam satu benang merah, yaitu sama-sama mengusung nilai-nilai mobilitas, kecepatan, teknologi, urbanisasi, pusat kota, yang merepresentasikan nilai-nilai dan kultur modernitas. Ritzer (2018) dan Ritzer (Smart (1999) mengartikan McDonaldisasi sebagai implikasi global dari produk McDonald's dengan ide dan nilai-nilai rasionalitas yang diusung, seperti modernitas, efisensi, kecepatan, perhitungan, kontrol mesin dan otomatisasi, homogenisasi sistem dan budaya konsumsi yang mengglobal, dan lain-lain. Dengan kata lain, signage yang demikian turut mendukung katalisasi "McDonaldisasi".

Lebih lanjut soal modernitas, signage Mcdonald's drive thru sebagai media dan karya desain, dapat dianggap sebagai karya pop art yang identik dengan dunia industri/komersial kontemporer. Pop art sejak kemunculannya di Amerika pada 1960-an, menurut Sandberg (1967), cenderung menampilkan dan mempromosikan budaya massa dan budaya konsumsi kontemporer, terutama sejak kemunculannya di Amerika, seperti makanan. Lebih lanjut, Sanberg menyebutkan, karya pop art seringkali menampilkan merek-merek dari produk yang dipromosikan. Dari pengertian ini, ditekankan pada objek material karya, tujuan, dari mana serta siapa yang mengusung pop art. Maka berdasarkan konsep ini, dapat kita ketahui bahwa signage drive thru dengan merek McDonald's dalam logo " $\mathrm{M}$ " dihadirkan untuk mempromosikan budaya populer (budaya pop/pop culture) McDonald's dan Amerika. Dalam hal ini, budaya pop mencakup kebiasaan dan pola konsumsi masyarakat urban yang erat dengan makanan cepat saji dan drive thru. Kehadiran signage tersebut sebagai instrumen untuk mempropagandakan komersialisme dan konsumerisme kehidupan modern, yang dalam hal ini melalui "cara modern", drive thru dan konsumsi makanan cepat saji. Sehingga bisa dikatakan, karakter signage sebagai pop art tersebut dianggap memiliki sifat depersonalisasi dan dehumanisasi. Karena cenderung merawat kesuburan konsumerisme publik. Kendati di Amerika sendiri, sebagian mengidentikkannya dengan makanan murah dan kebiasaan tidak sehat, di pasar dunia ia dianggap merepresentasikan kesenangan (Cowin \& Matusitz, 2016).

Sokongan kokoh dan profesional atas budaya komersialis dan konsumeris ini juga dilihat dari dukungan penempatan dan perawatan pada signage sebagai media promosi luar ruang. Pemilihan lokasi dan posisi yang mudah dan strategis dilihat pengendara/pengguna jalan, serta penjagaan terhadap gangguan yang menghalangi penglihatan seperti pohon, bangunan, maupun distraksi tanda (sign) lainnya, misalnya terlihat dari jarah jauh (100 meter) sebagaimana disebutkan di muka, menunjukkan kesan bahwa signage dan entitas yang diwakilinya (McDonald's) "berkuasa" atas ruang (lingkungan spasial) sekitarnya, meliputi lingkungan bangunan, masyarakat, dan sebagainya. Kuasa atas ruang publik (dalam rangka meraih perhatian pasar -pengguna jalan-) menunjukkan kekuasaan modal yang besar. Sehingga hal tersebut mengindikasikan kekuasaan modal kapital dan bisa diasumsikan sebagai upaya memenangkan kontestansi pasar, atau bahkan menunjukkan superioritas pasar.

\section{Kesimpulan}

Fungsi signage McDonald's drive thru sebagai media komunikasi visual (promosi luar ruang) diketahui tidak hanya dipahami secara tekstual saja, yaitu kaitannya dengan fungsi pemasaran, namun juga mempromosikan McDonaldisasi, kapitalisme, konsumerisme, modernisasi, gaya 
hidup pop dan pop art, serta kehidupan urban.

\section{Kepustakaan}

Azcentral.com. (2016). You won't believe where McDonald's opened its Diunduh di https://www.azcentral.com/story/travel/arizon a/2016/08/29/mcdonalds-first-drive-throughsierra-vista-arizona/88009974/ tanggal 18 September 2020

Barker, Chris. (2015). Cultural Studies, Teori dan Praktik. Terjemahan Nurhadi. Bantul: Kreasi Wacana

Calori, Chris dan Vanden-Eynde, David. (2015). Signage and Wayfinding Design. New Jersey: John Wiley \& Sons, Inc.

Cowin, Erica \& Matusitz, Jonathan. (2016). The Ongoing Transformation of the McDonald's Logo: A Semiotic Perspective. Journal of Visual Literacy, 30(2): 20-38. Routledge, Taylor and Francis

Designhill. (2018). McDonald's Iconic Logo The Story Of Its Evolution. Diunduh di https://www.designhill.com/designblog/mcdonalds-iconic-logo-story-evolution/ tanggal 8 Oktober 2020

Forbes. (2020). The World's Most Valuable Brands. Diunduh di https://www.forbes.com/the-worlds-mostvaluable-brands/\#7c20ca0d119c, tanggal 8 Oktober 2020

Love, John F. (1995). McDonald's: Behind the Arches. Amerika Serikat: Bantam Books

McDonald's Indonesia. (2020). Lokasi. [Online] Diunduh di https://mcdonalds.co.id/about tanggal 5 September 2020

McDonald's Corporation. (2015). McDonald's history. Diunduh di http://www.aboutmcdonalds.com/mcd/our_c ompany/mcdonalds-history.html. tanggal 5 September 2020

O'Neill, Bruce. (2020). Segmenting the city: McDonald's, the Metro, and the mobilization of the middle classes underground. EPA: Economy and Space, 52(7): 1313-1331. SAGE Publication
Penfold, Steve. (2008). The Donut: A Canadian History. Canada: University of Toronto Press

Ritzer, G. (1999). Assessing the resistance. dalam Smart, B. (Ed), Resisting McDonaldization. London: SAGE Publication

Ritzer, G. (2018). McDonaldization. The Blackwell Encyclopedia of Sociology, 1-3. John Wiley \& Sons, Ltd

Ritzer, G. (2018). The McDonaldization of Society: Into the Digital Age, 9th, Thousand Oaks, CA: SAGE Publication

Rodrigues, Rita., Coelho, Rita., \& Tavares, Joao Manuel R. S. (2020). Users Perceptions of Signage Systems at Three Portuguese Hospitals. Health Environments Research \& Design Journal. 13(3): 36-53. SAGE Publication

Sandberg, John. (2015). Some Traditional Aspects of Pop Art. Art Journal, 26(3): 228245. Routledge, Taylor and Francis

Smith, Andrew F. (2006). Encyclopedia of Junk Food and Fast Food. Amerika Serikat: Greenwood Press

Smith, Andrew F. (2013). Food and Drink in American History: A Full Course Encyclopedia. California: ABC-CLIO, LLC

Statista. (27 April 2020). McDonald's - Statistics \& Facts. Diunduh di https://www.statista.com/topics/1444/mcdon alds/, tanggal 8 Oktober 2020

Statista. (1 Juli 2020). Brand Value of 10 Most Valuable Quick Service Restaurants Brands Worldwide in 2020. Diunduh di https://www.statista.com/statistics/273057/val ue-of-the-most-valuable-fast-food-brandsworldwide/, tanggal 8 Oktober 2020

Tripdomestik.com. (2018). Diunduh di http://tripdomestik.com/static/upload/ 2014/05/21/20140521_140609_1268.jpg. tanggal 8 Oktober 2020

Ui Xie, Lazaros Filippidis, Steven Gwynne, Edwin R. Galea, Darren Blackshields and Peter J. Lawrence. (2007) Signage Legibility Distances as a Function of Observation Angle. Journal of Fire Protection Engineering, SAGE Publicatiom 
Waymarking.com. (2008) FIRST- McDonald's Drive Thru. Diunduh di https://www.waymarking.com/waymarks/W M3VDP_FIRST_McDonalds_Drive_Thru_S ierra_Vista_AZ Tanggal 18 September

Whitbread, David. (2001). The Design Manual. Sydney: University of New South Wales Press
(UNSW) Ltd

Zijlstra, E., Hagedoorn, M., Krijnen, W. P., van der Schans, C. P., \& Mobach, M. P. (2016). Route complexity and simulated physical ageing negatively influence wayfinding. Applied Ergonomics, 56, 62-67. Elsevier 